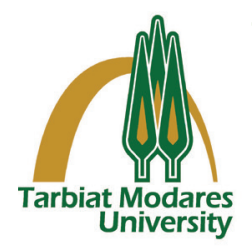

\title{
In Vitro Antifungal Susceptibility Profiles of Dermatophytes Isolates from Tinea Capitis in Northwest, Nigeria
}

\section{A R T I C L E I N F O}

Article Type

Original Research

Authors

Hussain Yahaya Ungo-kore, $M S c^{1^{*}}$ Joseph Olorunmola Ehinmidu, $M S c^{2}$ Josiah Ademola Onaolapo, $M S c^{2}$ Olayeni Stephen Olonitola, $M S c^{3}$

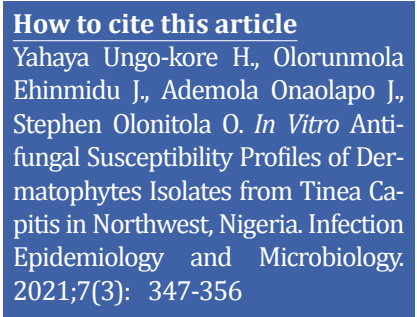

${ }^{1}$ Department of Pharmaceutics and Pharmaceutical Microbiology, Faculty of Pharmaceutical Sciences, Usmanu Danfodiyo University. ${ }^{2}$ Department of Pharmaceutical Microbiology, Faculty of Pharmaceutical Sciences, Ahmadu Bello University, Zaria ${ }^{3}$ Department of Microbiology, Faculty of Life Sciences, Ahmadu Bello University, Zaria, Kaduna

\begin{abstract}
* Correspondence
Address: Department of Microbiology, Faculty of Life Sciences, Ahmadu Bello University, Zaria, Kaduna 1044, Nigeria

hussaini.yahaya@udusok.edu.ng
\end{abstract}

\begin{abstract}
A B S T R A C T
Background: The fungal infection of tinea capitis is a common mycosis that affects the scalp superficially, especially in children. Oral treatment of this infection remains the preferred treatment process in clinical dermatology. Many antifungals available for dermatophyte treatment lead to treatment failure. Determination of antifungal susceptibility of dermatophytes in-vitro has been reported to be important to curb dermatophyte infections using effective antifungal drugs. The aim of this study was to investigate and determine in vitro minimum inhibitory concentration (MIC) of amphotericin B, ketoconazole, griseofulvin, terbinafine, and fluconazole against dermatophyte clinical isolates using agar dilution method.

Materials and Methods: In this study, in vitro susceptibilities of 32 dermatophyte clinical isolates collected from primary school pupils in Sokoto metropolis were investigated to five antifungals (fluconazole, terbinafine, ketoconzole, amphotericin B, and griseofulvin) using the CLSI agar dilution method.

Findings: The results obtained revealed that griseofulvin and terbinafine were the most potent antifungal agents among those tested.

Conclusion: Agar dilution method could be an alternative method for MIC-determination of antifungal drugs against dermatophyte species, since it is cost effective and affordable with consistent results, especially in developing countries.
\end{abstract}

\section{Keywords: Dermatophytes, Tinea capitis, Antifungal susceptibility testing, Nigeria}

\section{CITATION LINKS}

[1] Aktas AE, Yigit N, Aktas A, Gozubuyuk SG. Investigation of ... [2] Assob JCN, Nsagha DS, Njouendou AJ, Zofou D, Sevidzem WF, Ketchaji A, et al. Diseases in ... [3] Ayodele EH, Charles N, Abayomi F. Prevalence, identification, and ... [4] Badali H, Mohammadi R, Mashedi O, de Hoog GS, Meis JF. In vitro susceptibility patterns of ... [5] Baghi N, Shokohi T, Badali H, Makimura K, Rezaei-Matehkolaei A, Abdollahi M, et al. In vitro ... [6] Campana EH, Carvalhaes CG, Nonato B, Antonia M de, Machado O, Gales AC. Comparison of MICE ... [7] Coelho LM, Aquino-Ferreira R, Maffei CML, Martinez-Rossi NM. In vitro ... [8] Dambuza IM, Wagener J, Brown GD, Gow NA. Immunology of fungal .... [9] Deng S, Ansari S, Ilkit M, Rafati H, Hedayati MT, Taghizadeh-Armaki M, et al. In vitro antifungal .... [10] Fattahi A, Shirvani F, Ayatollahi A, Rezaei-Matehkolaei A, Badali H, Lotfali E, et al. Multidrug-resistant ... [11] Ferguson L, Fuller LC. Spectrum and burden of dermatophytes in children. J ... [12] Ghuse V, Someshwar S, Jerajani H. Patterns of culture positivity and ... [13] Gracia Paul L. ERG11 expression in azole resistant Candida ... [14] Gupta AK, Foley KA, Versteeg SG. New antifungal agents and new ... [15] Humphries RM, Hindler JA. Emerging resistance, new antimicrobial agents... but no tests! The ... [16] HY U, Ibrahim YKE, Tytler BA. Anti-dermatophytic activity of ... [17] Leung AK, Hon KL, Leong KF, Barankin B, Lam JM. Tinea capitis: An updated ... [18] Mikaeili A, Kavoussi H, Hashemian AH, Gheshtemi MS, Kavoussi R. Clinico-mycological profile ... [19] Newland JG, Abdel-Rahman SM. Update on terbinafine with a focus on ... [20] Nweze EI, Eke IE. Dermatophytes and dermatophytosis in the eastern and southern parts of Africa [21] Osborne CS, Leitner I, Hofbauer B, Fielding CA, Favre B, Ryder NS. Biological, biochemical, and molecular ... [22] Pérez-Tanoira R, Marín I, Berbegal L, Prieto-Pérez L, Tisiano G, Cuadros J, et al. Mycological profile of ... [23] Pharmacopoeia B. British ... [24] Rezaei-Matehkolaei A, Makimura K, Graser Y, Seyedmousavi S, Abastabar M, Rafiei A, et al. Dermatophytosis due ... [25] Singal A, Rawat S, Bhattacharya SN, Mohanty S, Baruah MC. Clinico-mycological profile of ... [26] Singh A, Masih A, Khurana A, Singh PK, Gupta M, Hagen F, et al. High terbinafine ... [27] Therese KL, Bagyalakshmi R. In-vitro susceptibility testing by ... [28] Tomar RS, Sharma P, Sharma A, Mishra R. Assessment and evaluation of ... [29] Wingfield Digby SS, Hald M, Arendrup MC, Hjorth SV, Kofoed K. Darier disease complicated by terbinafine-resistant A case report. Acta Derm ...

\section{Article History}

Received: March 052021

Accepted: April 25,2021

Published: November 05,2021

Copyright(C) 2021, TMU Press. This open-access article is published under the terms of the Creative Commons Attribution-NonCommercial 4.0 International License which permits Share (copy and redistribute the material in any medium or format) and Adapt (remix, transform, and build upon the material) under the Attribution-NonCommercial terms. 


\section{Introduction}

Tinea capitis (scalp dermatophytosis) is an inflammatory dermatophytosis of the scalp, which is a chronic and highly contagious infection distributed worldwide. This disease is the most common superficial mycosis that infects children between the ages of 4 to 14 years and regarded as a major public health concern ${ }^{[1]}$.

Treatment of such an infection mostly requires oral administration of antifungal drugs to penetrate the hair shaft ${ }^{[2]}$. Most treatments of superficial dermatophytosis are solely based on the use of topical and systemic antifungal agents. Recently, safe, affordable, and highly effective antifungal agents have been introduced into clinical practice ${ }^{[1]}$. Antifungal drugs used in the treatment of superficial mycosis have advantages and disadvantages in the field of epidemiology with increased drug resistance and recalcitrance without a similar study in this domain. With the introduction of griseofulvin in 1958, anthropophilic agents of tinea capitis, including Trichophyton spp. and Microsporum spp., were almost eradicated in most parts of the world ${ }^{[3]}$. Currently, tinea capitis is prevalent mainly in African countries (Nigeria and Ethiopia) and western China and in general in geographical regions where lifestyles are mostly associated with malnutrition and poverty. This infection has also been reported occasionally in Nigeria ${ }^{[4,5]}$. A prevalence rate of $75.7 \%$, resistance of $21.2-$ $100 \%$, and sensitivity of 78.8-100\% have been reported in north central Nigeria for T. rubrum as the most prevalent dermatophyte ${ }^{[6]}$, while T. verrucosum has been shown to be the most prevalent isolate in Ethiopia ${ }^{[7]}$.

Due to the increasing incidence of resistance, in vitro antifungal susceptibility tests are frequently used to determine the drug of choice among the available antifungal agents [8]. Despite good in vitro activity of TRB (terbinafine) against several anthropophilic and zoophilic species, several recent surveys have reported the growing incidence of TRB resistance among dermatophytes. It seems that the global spread of terbinafine-resistant Trichophyton strains with point mutations in the squalene epoxidase (SQLE) gene is a great concern. Resistant isolates have also been reported recently in Asia and Europe. Therefore, the following reference has missed its credibility because of fully resistant isolates reported to terbinafine [9]. In vitro activity of TRB has been reported against some dermatophyte species such as T. rubrum, $T$. mentagrophytes/interdigitale, T. schoenleini, and Epidermophyton floccosum [10].

In order to determine the ability of a given antifungal agent to eliminate dermatophytes causing tinea infection and to help manage patients, determination of in vitro antifungal susceptibility of dermatophytes would be helpful in understanding an unsuccessful or successful treatment [11]. However, not all species have the same susceptibility pattern, and it may be necessary to perform in vitro susceptibility testing to select and monitor antifungal therapy ${ }^{[12]}$.

Some methods used for antifungal sensitivity testing include: National Committee for Clinical Laboratory Standards NCCLS - the new name of Clinical Laboratory Standards Institute (CLSI) broth based methodology (M 27-A), CLSI methodology for moulds, E-test agar based testing methods, flow cytometry, and the use of viability dyes. These methods are time consuming and labour intensive; hence, a more economical method such as agar dilution have been described ${ }^{[13]}$.

Objectives: The present study focused on in vitro agar dilution method to determine minimum inhibitory concentration (MIC) of amphotericin B, ketoconazole, griseofulvin, terbinafine, and fluconazole against dermatophyte clinical isolates.

\section{Material and Methods}

Fungal strains: In this study, T. rubrum 
ATCC 28188 was included for invitro susceptibility testing based on the guidelines of CLSI, which state ideal reference strains for quality control of all antifungal drugs. A total of 32 clinical dermatophyte strains (Accession Number MT 893932 - MT 893963) were isolated from primary school pupils suspected with tinea capitis infection in Sokoto State metropolis, Nigeria from May to December 2020. An informed consent form was signed and approved by each of the participants. All isolates were cultured on Sabouraud dextrose agar (Oxoid, Basingstoke, U.K.) at $25{ }^{\circ} \mathrm{C}$ for 5 to 21 days and identified using sequence - based analysis of $28 S$ rRNA sequencing. The inocula (T. eriotrephon $=10$, T. bullosum $=2$, T. simii $=12, T$. benhamiae $=1$, T. rubrum=1, T. tonsurans $=3$, Microsporum audouinii $=2$, Ctenomyces serratus $=1$, and a reference strain of T. rubrum 28188) were then prepared spectrophotometrically using a spectrophotometer (Milton Roy company, Madrid Spain) and further diluted with normal saline in order to obtain a final inoculum concentration of $1 \times 10^{5} \mathrm{CFU} / \mathrm{mL}$. Preparation of stock solutions of standard antifungal agents: The in vitro susceptibilities of 32 dermatophyte clinical isolates to five antifungals were tested using CLSI agar dilution method guidelines according to Dambuza et al. (2017) ${ }^{[14]}$. Stock solutions of reference antifungal agents, including fluconazole, terbinafine, ketoconazole, amphotericin B, and griseofulvin (Sigma Aldrich, U.S.A), were prepared by dissolving appropriate quantity of the antifungal agents in $10 \% \mathrm{v} / \mathrm{v}$ dimethylsulfoxide (DMSO) (Sigma Aldrich, U.S.A.), water, and ethanol (Sigma Aldrich, U.S.A.), which were then diluted to the required concentrations using Sabouraud liquid medium (broth) (Oxoid, Basingstoke, U.K.). Final concentrations of the antifungal agents were as follows: amphotericin B: 0.125-32 $\mu \mathrm{g} / \mathrm{mL}$, ketoconazole: $0.875-28$ $\mu \mathrm{g} / \mathrm{mL}$, fluconazole: 1.68-53.76 $\mu \mathrm{g} / \mathrm{mL}$, griseofulvin: $0.25-16 \mu \mathrm{g} / \mathrm{mL}$, and terbinafine: 0.25-8 $\mu \mathrm{g} / \mathrm{mL}$.

Determination of MIC endpoints: The MIC (the lowest concentration of drug preventing the growth of microscopically visible colonies on drug-containing plates when there was visible growth on drug-free plates) readings were performed at the end of 48 hours of incubation, when growth appeared on the control plate, the time period was followed according to CLSI which recommended for 72 hours ${ }^{[5]}$. The criteria for susceptibility/ resistance testing of antifungal drugs using the peak plasma concentration were followed as previously described ${ }^{[15]}$. Thus, isolates that were sensitive to less than or equal to 4.00 $\mu \mathrm{g} / \mathrm{mL}$ of amphotericin $\mathrm{B}, 3.50$ of $\mu \mathrm{g} / \mathrm{mL}$ of ketoconazole, $6.72 \mu \mathrm{g} / \mathrm{mL}$ of fluconazole, $2.00 \mu \mathrm{g} / \mathrm{mL}$ of griseofulvin, and $1.00 \mu \mathrm{g} / \mathrm{mL}$

Table 1) Criteria for susceptibility/resistance to antifungal drugs

\begin{tabular}{lll}
\hline Antifungal Agent & Susceptible & Resistant \\
\hline & $\mu \mathrm{g} / \mathrm{mL}$ & $\mu \mathrm{g} / \mathrm{mL}$ \\
\hline Amphotericin B & $\leq 4.00$ & $>4.00$ \\
\hline Fluconazole & $\leq 6.72$ & $>6.72$ \\
\hline Griseofulvin & $\leq 2.00$ & $>2.00$ \\
\hline Terbinafine & $\leq 1.00$ & $>1.00$ \\
\hline Ketoconazole & $\leq 3.50$ & $>3.50$ \\
\hline
\end{tabular}


of terbinafine were considered as susceptible (Table 1). All experiments on each strain were performed using three independent replicates.

\section{Determination of Minimum fungicidal} concentration: The filter paper discs showing no visible growth in determining minimum inhibitory concentration were aseptically removed with the aid of a sterile forceps and transferred into 5.0 $\mathrm{mL}$ of sterile Sabouraud dextrose liquid medium containing $0.050 \% \mathrm{v} / \mathrm{v}$ glycerol and incubated at $30{ }^{\circ} \mathrm{C}$ for $48 \mathrm{hrs}$. Minimum fungicidal concentrations (MFC) were determined as the lowest concentration resulting in no growth in subculture [16]. Statistical analysis: The analysis of the qualitative data was conducted by means of Chi-square and Fisher's exact tests. A $p$-value less than .05 was considered statistically significant. Data analysis was performed in SPSS software (Version 12).

\section{Findings}

Antifungal susceptibility testing of Dermatophytes: Antifungal susceptibilities, involving MIC and MFC, of 32 clinical isolates of dermatophytes are shown in Tables 2 and 3. The MICs of griseofulvin (GF), ketoconazole (KTC), terbinafine (TBF), amphotericin B (AMB), and fluconazole (FLU) were determined for T. eriotrephon (10), T. bullosum (2), T. simii (12), T. benhamiae (1), T. rubrum (1), T. tonsurans (3), M. audouinii (2), C. serratus (1), T. rubrum 28188 (1), and others (8). As shown in Table 2, the MICs of AMB, KTC, FLU, GF, and TBF for most dermatophytes ranged between $0.125->32,0.875->28,1.68->53.76$, $0.25-\geq 16$, and $0.25-8 \mu \mathrm{g} / \mathrm{mL}$, respectively. The most frequent MICs of these antifungals against the isolates were $>32,0.875$ and 1.75, 3.36 and $>53.76,0.5$, and $0.25 \mu \mathrm{g} / \mathrm{mL}$, respectively. Additionally, the MFCs were 0.25 - >32, $0.875-28,3.36->53.76,0.25-$ 16 , and $0.5-8 \mu \mathrm{g} / \mathrm{mL}$ for AMB, KTC, FLU, GF, and TBF, respectively as shown in Table 3 . C. serratus was only susceptible to KTC and $\mathrm{TBF}$ at higher MIC values of 14 and $4 \mu \mathrm{g} / \mathrm{mL}$, respectively.

The MICs of AMB, KTC, FLU, GF, and TBF against all the isolates ranged from 0.5-

Table 2) MIC ranges of different antifungals against dermatophytes

\begin{tabular}{|c|c|c|c|c|c|}
\hline $\begin{array}{l}\text { Antifungal Agents } \\
(\mu \mathrm{g} / \mathrm{mL})\end{array}$ & AMB & KTC & FLU & GF & TBF \\
\hline T. eriotrephon $(n=10)$ & $(0.25->32)$ & $(0.875-28)$ & $(1.68->53.76)$ & $(0.25-1)$ & $(0.25-0.5)$ \\
\hline T. bullosum $(n=2)$ & $(0.125->32)$ & $(1.75-7)$ & $(1.68-3.63)$ & $(0.25-0.5)$ & $(0.25)$ \\
\hline T. simii $(n=12)$ & $(0.125->32)$ & $(1.75-7)$ & $(1.68-6.72)$ & $(0.25-0.5)$ & $(0.25-4)$ \\
\hline T. benhamiae $(n=1)$ & $(0.5)$ & $(0.875)$ & $(3.36)$ & $(0.5)$ & $(0.25)$ \\
\hline T. rubrum $(n=1)$ & $(0.25)$ & $(0.875)$ & $(>53.76)$ & $(0.5)$ & $(0.5)$ \\
\hline T. tonsurans $(n=3)$ & $(0.25->32)$ & $(1.75->28)$ & $(3.36->53.76)$ & $(0.25-16)$ & $(0.25-8)$ \\
\hline M. audouinii $(n=2)$ & (4) & $(3.5-7)$ & $(3.36-6.72)$ & $(0.5)$ & $(0.25-0.5)$ \\
\hline C. serratus $(n=1)$ & $(>32)$ & $(14)$ & $(>53.76)$ & $(>16)$ & $(4)$ \\
\hline Others $(n=8)$ & $(>32)$ & $(0.875->28)$ & $(1.68->53.76)$ & $(0.25-0.5)$ & $(0.25-4)$ \\
\hline T. rubrum (ATCC 28188) & $(0.25)$ & $(1.75)$ & $(3.36)$ & $(0.5)$ & $(0.5)$ \\
\hline
\end{tabular}


Table 3) MFC ranges of different antifungals against dermatophytes

\begin{tabular}{llllll}
\hline $\begin{array}{l}\text { Antifungal Agents } \\
(\boldsymbol{\mu g} / \mathbf{m L})\end{array}$ & AMB & KTC & FLU & GF & TBF \\
\hline T. eriotrephon $(\boldsymbol{n}=\mathbf{1 0})$ & $(0.5->32)$ & $(1.75->28)$ & $(3.36->53.76)$ & $(0.5-2)$ & $(0.5-1)$ \\
\hline T. bullosum $(\boldsymbol{n}=\mathbf{2})$ & $(0.25-32)$ & $(3.5-14)$ & $(3.63-6.72)$ & $(0.5-1)$ & $(0.25)$ \\
\hline T. simii $(\boldsymbol{n}=\mathbf{1 2})$ & $(0.25->32)$ & $(1.75-14)$ & $(3.36->53.76)$ & $(0.25-1)$ & $(0.5-8)$ \\
\hline T. benhamiae $(\boldsymbol{n}=\mathbf{1})$ & $(1)$ & $(0.875)$ & $(6.72)$ & $(1)$ & $(0.5)$ \\
\hline T. rubrum $(\boldsymbol{n}=\mathbf{1})$ & $(0.5)$ & $(1.75)$ & $(>53.76)$ & $(1)$ & $(1)$ \\
\hline T. tonsurans $(\boldsymbol{n}=\mathbf{3})$ & $(0.5-1)$ & $(3.5)$ & $(6.72-53.76)$ & $(0.5-16)$ & $(0.5-1)$ \\
\hline M. audouinii $(\boldsymbol{n}=2)$ & $(8)$ & $(3.5-14)$ & $(6.72-13.44)$ & $(1)$ & $(0.5-1)$ \\
\hline C. serratus $(\boldsymbol{n}=\mathbf{1})$ & $(>32)$ & $(28)$ & $(>53.76)$ & $(>16)$ & $(8)$ \\
\hline Others $(\boldsymbol{n}=\mathbf{8})$ & $(0.5->32)$ & $(1.75-28)$ & $(3.36->53.76)$ & $(0.5-1)$ & $(0.5-4)$ \\
\hline T. rubrum (ATCC 28188) & $(0.25)$ & $(1.75)$ & $(3.36)$ & $(0.5)$ & $(0.5)$ \\
\hline
\end{tabular}

$>32,1.75->28,3.36->53.76,0.5-16$, and $0.5-8 \mu \mathrm{g} / \mathrm{mL}$, respectively; thus, 34 (85\%), 23 (57.5\%), 33 (82.5\%), 38 (95\%), and 35 $(87.5 \%)$ isolates of dermatophytes were susceptible to AMB, KTC, FLU, GF, and TBF, respectively. Terbinafine and griseofulvin showed lower MIC values compared to fluconazole, ketoconazole, and amphotericin $B$; thus, they were the most potent agents against all the dermatophyte isolates.

The antifungal resistance pattern of dermatophyte isolates is shown in Table 4. According to the results, 10, 40, and 20\% of $T$. eriotrephon isolates were resistant to amphotericin $\mathrm{B}$, ketoconazole, and fluconazole, respectively. Also, $50 \%$ of $T$. bullosum strains were resistant to both AMB and KTC. About 8, 41, and 15\% of T. simii strains were resistant to AMB, KTC, and $\mathrm{TBF}$, respectively. T. benhamiae and T. rubrum isolates were susceptible to all the antifungal agents, except T. rubrum to FLU. Only $50 \%$ of $M$. audouinii strains were resistant to KTC. About 33\% of T. tonsurans isolates were resistant to $\mathrm{AMB}, \mathrm{KTC}, \mathrm{GF}$, and
TBF, while $66 \%$ were resistant to FLU. $C$. serratus was resistant to all of the antifungal agents. Out of 8 species tested, 4, 2, 5, 7, and 6 cases were resistant to TBF, GF, FLU, KTC, and AMB, respectively. Table 4 shows that 6 (15\%), 17 (42.5\%), 7 (17.5\%), 2 (5\%), and $5(12.5 \%)$ clinical isolates of dermatophytes were resistant to AMB, KTC, FLU, GF, and TBF, respectively. Some of these clinical isolates were multidrug resistant. As shown in the table, T. tonsurans and C. serratus were resistant to all the antifungal agents, and $T$. eriotrephon and T. simii were resistant to AMB and KTC. Only one isolate of T. simii was resistant to AMB, KTC, and TBF. This shows that most multidrug-resistant isolates were resistant to AMB and KTC.

Correlation of Antifungal Susceptibility Testing and gender of patients: The correlation of antifungal susceptibility testing of dermatophytes clinical isolates and gender showed that $20,50,55,8$, and $12.5 \%$ of dermatophytes isolates from males were resistant to AMB, KTC, FLU, GF, and TBF, respectively, while 17,31 , and $13 \%$ of the 
Table 4) Resistance distribution of dermatophytes to different antifungals

\begin{tabular}{llllll}
\hline \multicolumn{5}{c}{ Resistance against (\%) } \\
\hline $\begin{array}{l}\text { Antifungal Agents } \\
(\mu \mathrm{g} / \mathrm{mL})\end{array}$ & AMB $(>4)$ & KTC $(>3.5)$ & FLU (>6.72) & GF (>2) & TBF (>1) \\
\hline T. eriotrephon $(\mathrm{n}=10)$ & $1(10)$ & $4(40)$ & $2(20)$ & - & - \\
\hline T. bullosum $(n=2)$ & $1(50)$ & $1(50)$ & - & - & - \\
\hline T. simii $(n=12)$ & $1(8.3)$ & $5(41.7)$ & - & - & $2(15.4)$ \\
\hline T. benhamiae $(n=1)$ & - & - & - & - & - \\
\hline T. rubrum $(n=1)$ & - & - & $1(100)$ & - & - \\
\hline T. tonsurans $(n=3)$ & $1(33.3)$ & $1(33.3)$ & $2(66.7)$ & $1(33.3)$ & $1(33.3)$ \\
\hline M. audouinii $(n=2)$ & - & $1(50)$ & - & - & - \\
\hline C. serratus $(n=1)$ & $1(100)$ & $1(100)$ & $1(100)$ & $1(100)$ & $1(100)$ \\
\hline Others $(n=8)$ & $1(12.5)$ & $4(50)$ & $1(12.5)$ & - & $1(12.5)$ \\
\hline
\end{tabular}

isolates from females were resistant to $\mathrm{AMB}$, KTC, and FLU, respectively. This shows that resistance is markedly pronounced in males than in females with the highest percentage of resistance to ketoconazole. Less resistance to griseofulvin and terbinafine was observed in males but not in females (Table 5).

\section{Discussion}

In vitro analysis of antifungal activity of antifungal agents enables comparison between different antimycotics, which in turn may clarify the reasons for lack of clinical response and assist clinicians in choosing an effective therapy for their patients. However, it is important that the methodologies used for in vitro testing be standardized to facilitate the establishment of quality control parameters and interpretive breakpoints ${ }^{[17]}$. In this study, the MIC values of five antifungal agents (amphotericin B, fluconazole, griseofulvin, terbinafine, and ketoconazole) were investigated against different species of dermatophyte clinical specimens using the agar dilution method.
The most active agents against all dermatophytes species (T. eriotrephon, T. bullosum, T. simii, T. benhamiae. T. rubrum, T. tonsurans, M. audouinii. C. serratus, and others) were terbinafine with MIC ranges of $0.25-0.5,0.25,0.25-4,0.25,0.5$, $0.25-8,0.25-0.5,4$, and $0.25-4 \mu \mathrm{g} / \mathrm{mL}$ and griseofulvin with MIC ranges of $0.5-2,0.5-1$, $0.25-1,1,1,0.5-16,1,>16$, and $0.5-1 \mu \mathrm{g} /$ $\mathrm{mL}$, respectively. This finding is similar with the finding of another study by Badali et al. (2015) [18], evaluating the efficacy of nine antifungals $\mathrm{AMB}$, fluconazole, itraconazole, voriconazole, posaconazole, isavuconazole, caspofungin, anidulafungin, and terbinafine) and reporting terbinafine as the most effective drug. This finding is not similar with the finding of another study by Coelho et al. (2008) [19], comparing in vitro antifungal susceptibility of the microconidia of $T$. rubrum and $T$. tonsurans to five commonly used drugs (AMB, fluconazole, terbinafine, itraconazole, and griseofulvin) and reporting $\mathrm{AMB}$ as the most superior drug. Also, the current study findings are in 
tandem with the findings of Aktas et al. (2014) ${ }^{[20]}$, reporting AMB to be consistently better than ketoconazole and fluconazole against all the dermatophytes tested [21, 22 . A study in northern India also showed that there was a good response to griseofulvin therapy among the tinea capitis patients, which agrees with the present study finding. With the emergence of treatment failure with griseofulvin, allylamines became the preferred choice of treatment, which is in agreement with this study findings clearly showing less resistance to terbinafine; thus, terbinafine becomes an alternative in case of griseofulvin failure.

These two drugs (terbinafine and griseofulvin) had the least resistant isolates (five and two, respectively). Resistance to

Table 5) Correlation of antifungal susceptibility testing and gender of patients

\begin{tabular}{|c|c|c|c|c|c|}
\hline $\begin{array}{l}\text { Antifungal Agents } \\
(\mu \mathrm{g} / \mathrm{mL})\end{array}$ & AMB & KTC & FLU & GF & TBF \\
\hline \multicolumn{6}{|c|}{ T. Eriotrephon $(n=10)$} \\
\hline Male $(n=6)$ & $(0.5->32)$ & $(1.75-28)$ & $(1.68->53.76)$ & $(0.25-1)$ & $(0.25-0.5)$ \\
\hline Female $(n=4)$ & $(0.5-4)$ & $(0.875-7)$ & $(1.68-3.36)$ & $(0.25-0.5)$ & $(0.25-0.5)$ \\
\hline \multicolumn{6}{|l|}{ T. bullosum $(n=2)$} \\
\hline Male $(n=2)$ & $(0.125->32)$ & $(1.75-7)$ & $(1.68-3.36)$ & $(0.25-0.5)$ & $(0.25)$ \\
\hline \multicolumn{6}{|l|}{ T. simii $(n=12)$} \\
\hline Male $(n=6)$ & $(0.125->32)$ & $(0.875-7)$ & $(1.68-6.72)$ & $(0.25-0.5)$ & $(0.25-4)$ \\
\hline Female $(n=6)$ & $(0.125-4)$ & $(1.75-7)$ & $(1.68-6.72)$ & $(0.25-0.5)$ & $(0.25-0.5)$ \\
\hline \multicolumn{6}{|l|}{ T. benhamiae $(n=1)$} \\
\hline Female $(n=1)$ & $(0.5)$ & $(0.875)$ & $(3.36)$ & $(0.5)$ & $(0.25)$ \\
\hline \multicolumn{6}{|l|}{ T. rubrum $(n=1)$} \\
\hline Male $(n=1)$ & $(0.25)$ & $(0.875)$ & $(>53.76)$ & $(0.5)$ & $(0.5)$ \\
\hline \multicolumn{6}{|l|}{ T. tonsurans $(n=3)$} \\
\hline Male $(n=2)$ & $(0.5->32)$ & $(1.75->28)$ & $(3.36->53.76)$ & $(0.5->16)$ & $(0.25->8)$ \\
\hline Female $(n=1)$ & $(0.25)$ & $(1.75)$ & $(>53.76)$ & $(0.5)$ & $(0.25)$ \\
\hline \multicolumn{6}{|l|}{ M. audouinii $(n=2)$} \\
\hline Male $(n=1)$ & $(4)$ & $(3.5)$ & $(3.36)$ & $(0.5)$ & $(0.5)$ \\
\hline Female $(n=1)$ & $(4)$ & (7) & $(6.72)$ & $(0.5)$ & $(0.25)$ \\
\hline \multicolumn{6}{|l|}{ C. serratus $(n=1)$} \\
\hline Male $(n=1)$ & $(>32)$ & $(14)$ & $(>53.76)$ & $(>16)$ & $(4)$ \\
\hline \multicolumn{6}{|l|}{ Others $(n=8)$} \\
\hline Male $(n=5)$ & $(0.125-4)$ & $(1.75$ - >28) & $(1.68->3.36)$ & $(0.25-0.5)$ & $(0.25-0.5)$ \\
\hline Female $(n=3)$ & $(0.25->32)$ & $(0.875-7)$ & $(1.68->3.36)$ & $(0.5)$ & $(0.25-0.5)$ \\
\hline
\end{tabular}


terbinafine is not far-fetched as some studies reported such resistance. Some studies have reported documented cases of terbinafineresistant $T$. rubrum [23, 24]. The least active agent was ketoconazole with MIC ranges of $0.875-28,1.75-7,1.75-7,0.875,0.875$, 1.75- >28, 3.5-7, 14, and 0.875- > $28 \mu \mathrm{g} / \mathrm{mL}$ against 17 resistant isolates.

With respect to terbinafine, all of $T$. eriotrephon, T. bullosum, T. benhamiae. T. rubrum, and $M$. audouinii isolates were inhibited at concentrations ranging from 0.25 to $0.5 \mu \mathrm{g} / \mathrm{mL}$. Some isolates of T. simii (2), T. tonsurans (1), C. serratus (1), and others (1) showed different sensitivity at high ranges. The same sensitivity pattern was observed to griseofulvin for T. eriotrephon, $T$. bullosum, T. simii, T. benhamiae. T. rubrum, M. audouinii, and others, ranging from 0.5 to $0.1 \mu \mathrm{g} / \mathrm{mL}$. T. tonsurans (1) and C. serratus (1) had high MIC values.

In this study, 17 (42.5\%) isolates of dermatophytes tested by agar dilution, including T. eriotrephon (4), T. bullosum (1), T. simii (5), T. tonsurans (1), M. audouinii (1). C. serratus (1), and others (4), were resistant to ketoconazole with a MIC range of $\geq 3.5 \mu \mathrm{g} /$ $\mathrm{mL}$. Also, 6 (15\%) isolates of dermatophytes tested by agar dilution, including $T$. eriotrephon (1), T. bullosum (1), T. simii (1), T. tonsurans (1), C. serratus (1), and others (1), were resistant to $\mathrm{AMB}$ with a MIC range of $\geq 3.5 \mu \mathrm{g} / \mathrm{mL}$. In addition, $7(17.5 \%)$ isolates, including T. eriotrephon (2), T. rubrum (1), T. tonsurans (2), C. serratus (1), and others (1), were resistant to FLU with a MIC range of $\geq$ $6.72 \mu \mathrm{g} / \mathrm{mL}$.

Antifungal susceptibility testing is a dynamic field, especially in medical mycology. Development and standardization of antifungal susceptibility test have shown remarkable progress in this field [17], although the use of agar dilution method for dermatophytes susceptibility testing is much sufficient. Most studies have showed that agar dilution seems to be an alternative method to MIC-determination of antifungal drugs for dermatophytes, especially in underdeveloped countries, though it is a laborious methodology, but results could be obtained faster and more cost-effectively [25]. Examination of the resistance of dermatophytic clinical isolates to five antifungal agents showed that this resistance was prominent in males compared to their female counterpart. The study also found that none of the clinical isolates from female was resistant to terbinafine and griseofulvin. Mikaeili et al. (2019) ${ }^{[26]}$. reported that males responded better when treated with terbinafine and griseofulvin [27], which is inconsistent with this study findings showing that dermatophyte clinical isolates from female responded better to griseofulvin and terbinafine. Another study in Nigeria reported terbinafine as the most active antifungal agent against dermatophytes ${ }^{[28]}$. Study limitation: The sample collection from children was tasking and timeconsuming, and internet service was also limited for efficient and effective write-ups.

\section{Conclusion}

In conclusion, our results revealed that griseofulvin and terbinafine were the most potent antifungals against dermatophytic fungi among systemic antifungals tested. It is worthy to note that more clinical data are needed to confirm if this potent efficacy in vitro is predictive of clinical outcome; however, at the interim, this finding will provide bases for choosing appropriate treatments for tinea infection in Nigeria hospitals.

\section{Acknowledgments}

We thank all the staff of Usmanu Danfodiyo University, Sokoto, Nigeria, especially personnel in Molecular Biology Laboratory at Faculty of Veterinary medicine, Usmanu 
Danfodiyo University, Sokoto.

Ethical Permission: The study was approved by the Ethics Committee of Sokoto State Ministry of Health (SKHREC/088/017, 29/12/2017).

Conflict of interest:: The authors report no conflicts of interest. The authors alone are responsible for the content and the writing of the paper

Authorship Contributions: Conceptualiztion: UHY, EJO, JAO, OSO; data curation: UHY; Formal analysis: UHY ; Investigation: UHY, EJO, JAO, OSO; Writing of the original draft: UHY ; Writing-review and editing: UHY.

Fundings: The authors declared that this study received no financial support.

Consent to participate: Informed consent was obtained from all subjects involved in the study.

\section{References}

1. Gupta AK, Foley KA, Versteeg SG. New antifungal agents and new formulations against dermatophytes. Mycopathologia. 2017;182(12): $127-41$.

2. Leung $\mathrm{AK}$, Hon KL, Leong KF, Barankin B, Lam JM. Tinea capitis: An updated re-view. Recent Pat Inflamm Allergy Drug Discov. 2020;14(1):58-68

3. Ferguson L, Fuller LC. Spectrum and burden of dermatophytes in children. J Infect. 2017;74(Suppl 1):S54-60.

4. Assob JCN, Nsagha DS, Njouendou AJ, Zofou D, Sevidzem WF, Ketchaji A, et al. Diseases in Africa: An overview. In: Medicinal spices and vegetables from Africa. Elsevier; 2017, pp. 1-69.

5. Deng S, Ansari S, Ilkit M, Rafati H, Hedayati MT, Taghizadeh-Armaki $\mathrm{M}$, et al. In vitro antifungal susceptibility profiles of 12 antifungal drugs against 55 Trichophyton schoenleinii isolates from tinea capitis favosa patients in Iran, Turkey, and China. Antimicrob Agents Chemother. 2017;61(2):e01753-16.

6. Ayodele EH, Charles N, Abayomi F. Prevalence, identification, and antifungal susceptibility of dermatophytes causing tinea capitis in a locality of north central nigeria. Afr J Infect Dis. 2021;15(1):1-9.

7. Pérez-Tanoira R, Marín I, Berbegal L, Prieto-Pérez L, Tisiano G, Cuadros J, et al. Mycological profile of tinea capitis in school children in rural southern Ethiopia. Med Mycol. 2017;55(3):262-8.
8. Baghi N, Shokohi T, Badali H, Makimura K, RezaeiMatehkolaei A, Abdollahi M, et al. In vitro activity of new azoles luliconazole and lanoconazole compared with ten other antifungal drugs against clinical dermatophyte isolates. Med Mycol. 2016;54(7):757-63.

9. Fattahi A, Shirvani F, Ayatollahi A, RezaeiMatehkolaei A, Badali H, Lotfali E, etal. Multidrugresistant Trichophyton mentagrophytes genotype VIII in an Iranian family with generalized dermatophytosis: Report of four cases and review of literature. Int J Dermatol. 2021;60(6):686-92.

10. Rezaei-Matehkolaei A, Makimura K, Graser Y, Seyedmousavi S, Abastabar M, Rafiei A, et al. Dermatophytosis due to Microsporum incurvatum: Notification and identification of a neglected pathogenic species. Mycopathologia. 2016;181(1-2):107-13

11. Ghuse V, Someshwar S, Jerajani H. Patterns of culture positivity and antifungal sensitivity in dermatophytosis. MGM J Med Sci. 2019;6 (3):105-12.

12. Humphries RM, Hindler JA. Emerging resistance, new antimicrobial agents but no tests! The challenge of antimicrobial susceptibility testing in the current US regulatory landscape. Clin Infect Dis. 2016;63(1):83-8.

13. Singh A, Masih A, Khurana A, Singh PK, Gupta $M$, Hagen $F$, et al. High terbinafine resistance in Trichophyton interdigitale isolates in Delhi, India harbouring mutations in the squalene epoxidase gene. Mycoses. 2018;61(7):477-84.

14. Dambuza IM, Wagener J, Brown GD, Gow NA. Immunology of fungal disease. Oxf Textb Med Mycol. 2017;62

15. Pharmacopoeia B. British pharmacopoeia. 2016.

16. HYU, Ibrahim YKE, Tytler BA. Anti-dermatophytic activity of hexane extracts of Azadirachta indica A. Juss. Afr J Microbiol Res. 2019;13(26):421-9

17. Gracia Paul L. ERG11 expression in azole resistant Candida species isolated from diabetic patients in a tertiary care centre [PhD Thesis]. Tirunelveli: Tirunelveli Medical College; 2019.

18. Badali H, Mohammadi R, Mashedi O, de Hoog GS, Meis JF. In vitro susceptibility patterns of clinically important Trichophyton and Epidermophyton species against nine antifungal drugs. Mycoses. 2015;58(5):303-7

19. Coelho LM, Aquino-Ferreira R, Maffei CML, Martinez-Rossi NM. In vitro antifun gal drug susceptibilities of dermatophytes microconidia and arthroconidia. J Antimi crob Chemother. 2008;62(4):758-61

20. Aktas AE, Yigit N, Aktas A, Gozubuyuk SG. Investigation of in vitro activity of five antifungal drugs against dermatophytes species 
isolated from clinical samples using the E-test method. Eurasian J Med. 2014;46(1):26-31.

21. Newland JG, Abdel-Rahman SM. Update on terbinafine with a focus on dermatophytoses. Clin Cosmet Investig Dermatol CCID. 2009;2:49-63.

22. Singal A, Rawat S, Bhattacharya SN, Mohanty $\mathrm{S}$, Baruah MC. Clinico-mycological profile of tinea capitis in north India and response to griseofulvin. J Dermatol. 2001;28(1):22-6.

23. Osborne CS, Leitner I, Hofbauer B, Fielding CA, Favre B, Ryder NS. Biological, biochemical, and molecular characterization of a new clinical Trichophyton rubrum isolate resistant to terbinafine. Antimicrob Agents Chemother. 2006;50(6):2234-6

24. Wingfield Digby SS, Hald M, Arendrup MC, Hjorth SV, Kofoed K. Darier disease complicated by terbinafine-resistant Trichophyton rubrum: A case report. Acta Derm Venereol. 2017;97(1):139-40.

25. Tomar RS, Sharma P, Sharma A, Mishra R.
Assessment and evaluation of methods used for antimicrobial activity assay: An overview. 2015;4(5):907-34.

26. Therese KL, Bagyalakshmi R, Madha van HN, Deepa P. In-vitro susceptibility testing by agar dilution method to determine the minimum inhibitory concentrations of amphotericin B, fluconazole, and ketoconazole against ocular fungal isolates. Indian J Med Microbiol. 2006;24(4):273-9.

27. Mikaeili A, Kavoussi H, Hashemian AH, Gheshtemi MS, Kavoussi R. Clinico-mycological profile of tinea capitis and its comparative response to griseofulvin versus terbinafine. Curr Med Mycol. 2019;5(1):15-20.

28. Nweze EI, Eke IE. Dermatophytes and dermatophytosis in the eastern and southern parts of Africa. Med Mycol. 2018;56 (1):13-28. 